\title{
Poverty and blindness in Nigeria
}

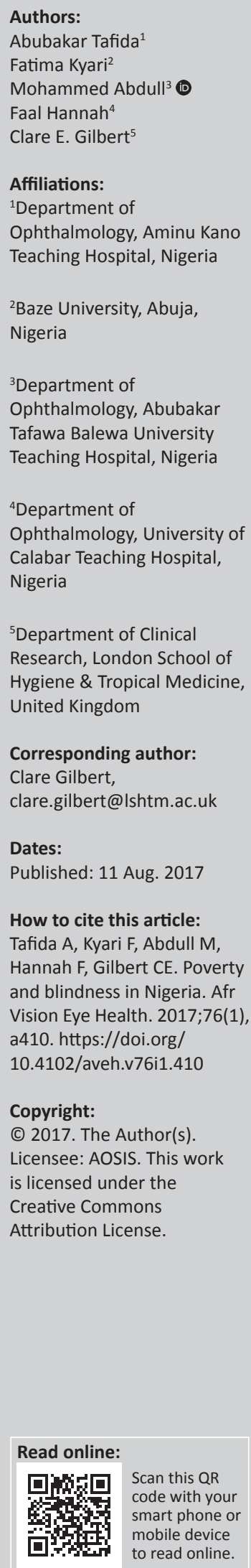

We appreciate the recent review of some of the papers arising out of the Nigeria National Survey of Blindness and Visual Impairment by Akano OF. We would like to draw readers' attention to our paper, which provides a detailed analysis of the association between indicators of poverty and blindness in Nigeria: Poverty and Blindness in Nigeria: Results from the National Survey of Blindness and Visual Impairment. Tafida A, Kyari F, Abdull MM, Sivasubramaniam S, Murthy GVS, Kana I, Gilbert CE. Nigeria National Survey of Blindness and Visual Impairment Study Group. Ophthal Epidemiol. 2015;22(5):333-341. https://doi.org/10.3109/09286586.2015.1077259.

\section{Acknowledgements Competing interests}

The authors declare that they have no financial or personal relationships that may have inappropriately influenced them in writing this letter.

\section{Authors' contributions}

All authors contributed equally to this letter. 